\title{
Metamaterial Loaded Rectangular Patch Antenna for Wireless Communication Application
}

\author{
Gayatri Vidhate ${ }^{1}$ \\ ${ }^{1}$ Assistant Professor, KIT's College of Engineering, Kolhapur,India
}

\begin{abstract}
In this paper, a metamaterial based compact multiband rectangular microstrip patch antenna is proposed. The return loss of metamaterial loaded microstrip patch antenna obtained at the resonant frequency $2.4 \mathrm{GHz}$. The metamaterial structure printed on FR4 substrate at hight of $1.6 \mathrm{~mm}$ from the ground plane. The FR4 substrate has 4.4 dielectric constant.These metamterial structures are periodic in nature and possesses negative permittivity and negative permeability. The greatest advantage of metamaterial loading will be miniaturization. This metamterial loaded rectangular patch antenna is simulated and tested using HFSS Simulator, where an electromagnetic analysis tool is used. The fabricated antennas results are measured using Vector Network Analyzer (VNA).
\end{abstract}

Key words : Complimentary Split Ring Resonators (CSRR), Double Positive(DPS), Double Negative(DNG), Metamaterial(MTM).

\section{INTRODUCTION}

Microstrip patch antenna is most widely used in various wireless communication applications like in mobile, satellite communication. Rectangular microstrip patch antenna is most popular because of its small size, low profile, and ease fabrication and feed [1].Microstrip patch antenna with low dielectric constant and thick substarte provides large bandwidth and better efficiency [5]. But it requires large dimensions. On the other hand if substrate with high dielectric constant is used then it affects the gain and bandwidth [2].So to overcome the above drawback metamaterials can be used. Metamaterials are used for further miniaturization of antenna. Metamaterials (MTM) are artificial structures which use different periodic structures to get the properties which are found in nature [6]. Conventional materials which are available in nature possesses basic properties a positive permittivity and permeability. Such materials are known as Double Positive (DPS) materials. Whereas metamterials are termed as Double negative (DNG) materials because of negative permittivity and permeability [4].

\section{ANTENNA DESIGN}

The metamaterial loaded rectangular patch antenna has been designed for $2.4 \mathrm{GHz}$. The FR4 substrate with 4.4 relative permittivity and $1.6 \mathrm{~mm}$ thickness is used. The inset fed microstrip patch antenna designed for $50 \Omega$ impedance.

The Figure 1 shows the geometry of proposed antenna.

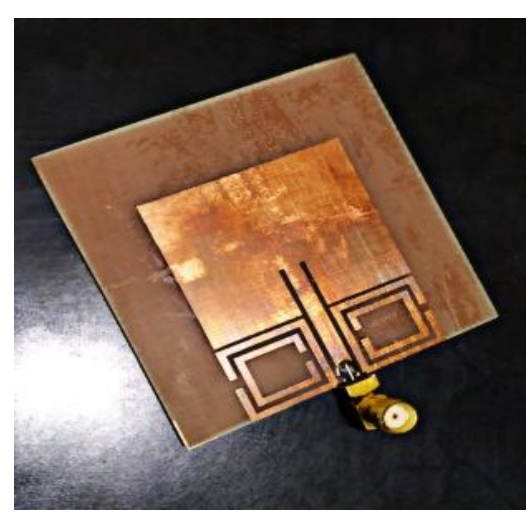

Figure 1: Rectangular Patch Antenna with Metamaterial Substrate (FR4 fabricated antenna)

Following equations are used to design the length and width of the patch [2];

$$
\begin{gathered}
\mathrm{W}=\frac{c}{2 f r} \sqrt{\frac{2}{\epsilon_{r}+1}} \\
\epsilon_{\text {reff }}=\frac{\epsilon_{r}+1}{2}+\frac{\epsilon_{r}-1}{2}\left[1+12 \frac{h}{W}\right]^{-\frac{1}{2}} \\
\frac{\Delta L}{h}=0.412 \frac{\left(\in_{\text {reff }}+0.3\right)\left(\frac{W}{h}+0.264\right)}{\left(\in_{\text {reff }}-0.258\right)\left(\frac{W}{h}+0.8\right)}
\end{gathered}
$$


Gayatri Vidhate, International Journal of Emerging Trends in Engineering Research, 9(3), March 2021, 193 - 197

$$
\mathrm{L}=\frac{c}{2 f_{r} \sqrt{\epsilon_{r e f f}}}-2 \Delta L
$$

Thus the conventional patch has been designed by using above mentioned formulas.

Among various feeding techniques, microstrip feed line is the easiest to construct. In microstrip feed line the conducting strip can be directly connected to the edge of the patch. The width of the feed line strip is very small as compared to the patch width. Furthermore, if inset cut is implemented into patch, impedance matching obtained very easily. In order to implement inset cut, the proper inset position has been find out with the help of online mictrostrip line calculator as shown in figure 2.we have to find out proper inset position.

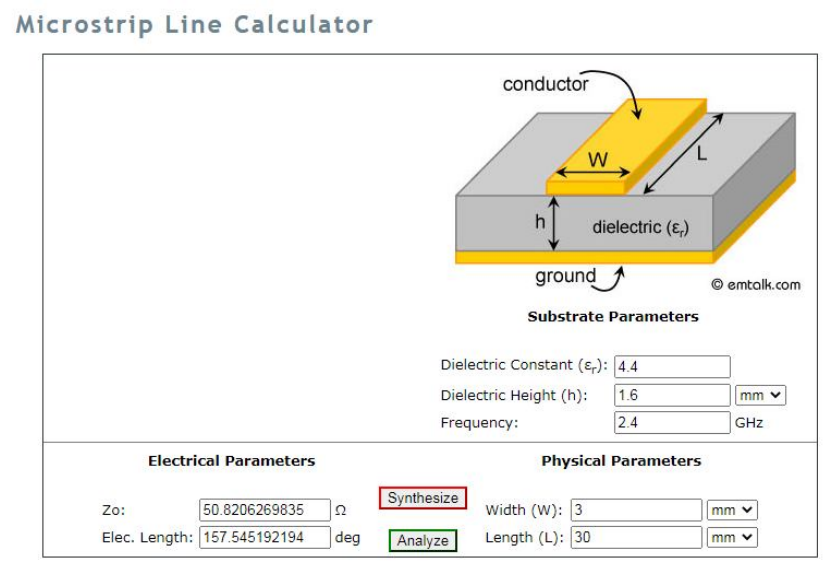

Figure 2: Microstrip Line Calculator [9]

By using inset feed, the impedance of the transmission line can be matched closer to the impedance of the centre of the patch as the transmission line is cut closer to it. This results in increment in current distribution as well as voltage in the patch [2].

The complementary split ring resonator has been placed at both the sides of feed line.

\section{METAMATERIAL GEOMETRY}

After obtaining the dimensions conventional patch, a complementary split ring resonator as a metamaterial structure is incorporated into the antenna design. Such a metamterial design printed on FR4 substrate which is having thickness $1.6 \mathrm{~mm}$. A rectangular complementary split ring resonator (CSRR) loaded microstrip patch antenna with an inset fed is designed.

The unit cell of proposed rectangular CSRR structure is shown in figure 3.

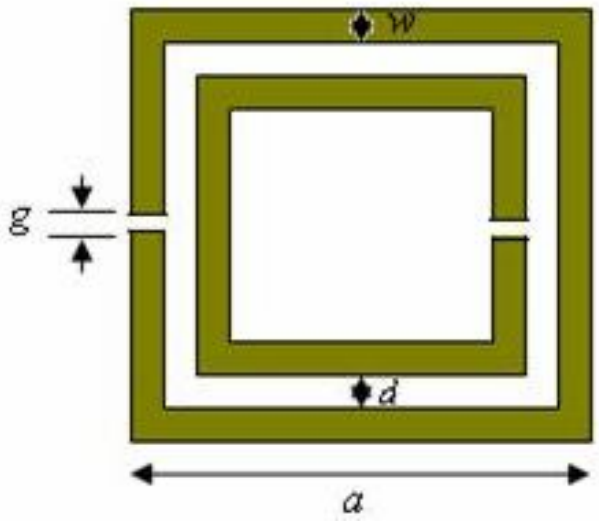

Figure 3: Unit cell of proposed rectangular CSRR Structure [3][7]

\section{DESIGN OF RECTANGULAR MICROSTRIP PATCH ANTENNA WITH METAMATERIAL}

Initially microstrip antenna, which is a rectangular patch, has been designed with a resonant frequency of $2.4 \mathrm{GHz}$. Then it is loaded with a metamaterial Complementary Split Ring Resonator structure near feed line. The ground plane and the patch with metamaterial structure are placed on opposite sides of FR4 substrate. The inclusion of the metamaterial results in miniaturization but reduces the gain which is the trade off with gain [5].

The figure 1 shows the fabricated antenna whereas figure 4 shows the designed antenna on simulation software.

Whenever there is metamaterial loading then the patch antenna's resonance frequency depends on metamaterial constitutive parameters. That means designed antenna resonates when metamaterial constitutive parameters becomes negative. Therefore resonance frequency of the antenna shifts to the metamaterial resonance frequency. So even though the patch antennas dimensions are as per the resonant frequency $2.4 \mathrm{GHz}$ but in results it shifts to $1.4 \mathrm{GHz}$ practically [8].

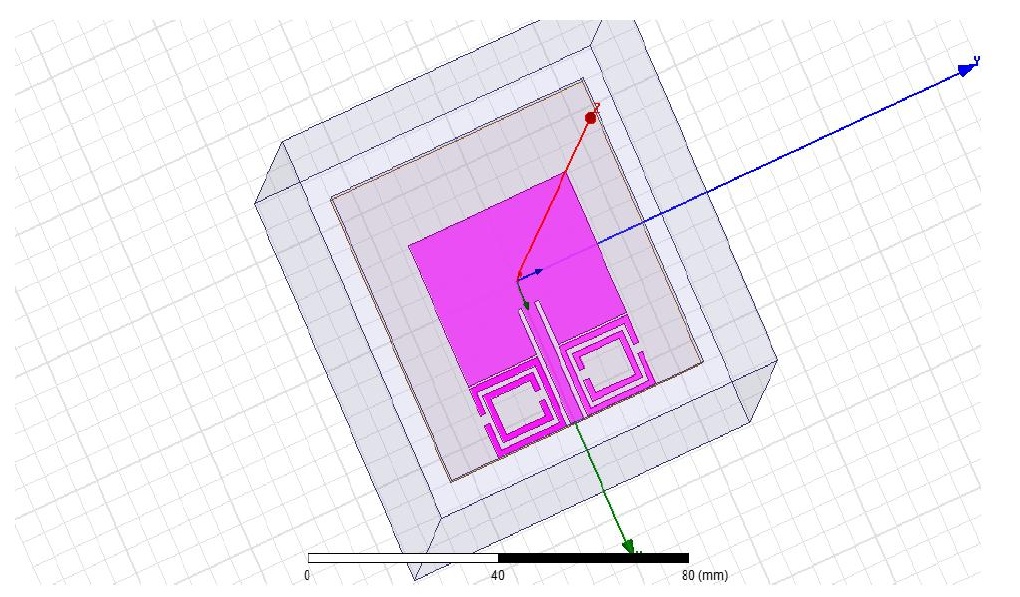

Figure 4: Inset Fed Metamaterial Loaded Microstrip Patch Antenna designed using Simulation Software 
Gayatri Vidhate, International Journal of Emerging Trends in Engineering Research, 9(3), March 2021, 193 - 197

\section{SIMULATION AND PRACTICAL RESULTS}

\subsection{Return Loss:}

The return loss of designed antenna and fabricated antenna is shown in figure 5 . It has been noted that the antenna with metamaterial achieves the low return losses. The simulated and measured return loss bandwidth extends from $1.4340-1.4580 \mathrm{GHz}$ and $1.5-1.6 \mathrm{GHz}$ respectively. It is measured using Rhode and Schwarz ZVL 135 Microwave Vector Network Analyzer of $13.6 \mathrm{GHz}$.

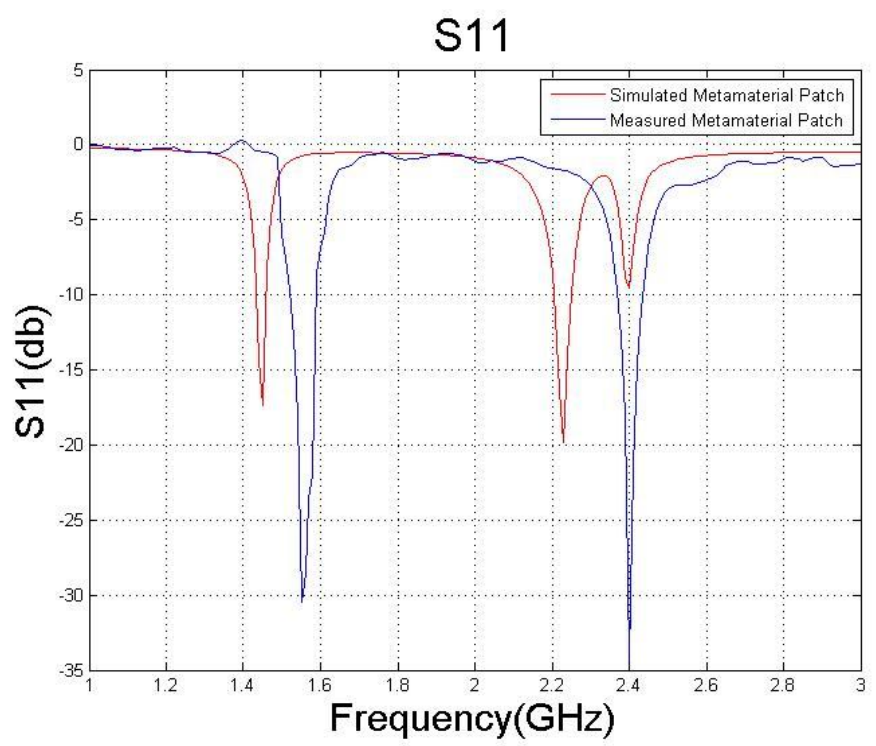

Figure 5: Simulated and measured return loss of inset fed metamaterial loaded microstrip patch antenna

\subsection{Radiation Pattern:}

The radiation pattern is a graphical depiction of the relative field strength transmitted from or received from by the antenna [8].

Figure 6 is the simulated radiation pattern in $\mathrm{XZ}$ plane at $1.4 \mathrm{GHz}$.

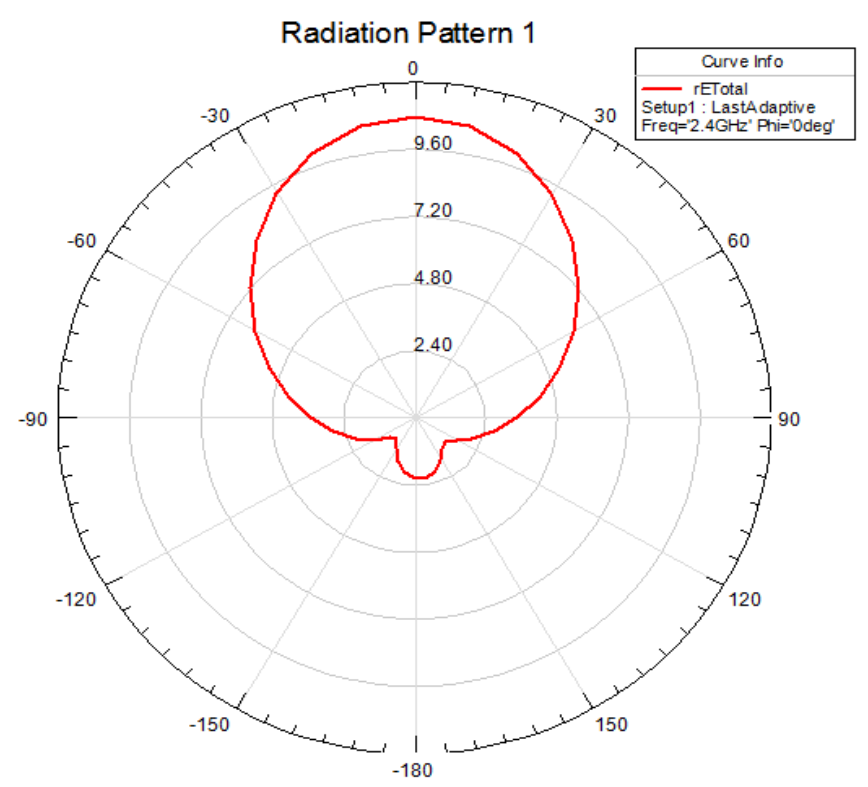

Figure 6: Simulated radiation pattern in the $\mathrm{XZ}$ plane at $1.4 \mathrm{GHz}$.

Figure 7 is the simulated radiation pattern in $\mathrm{YZ}$ plane at $1.4 \mathrm{GHz}$

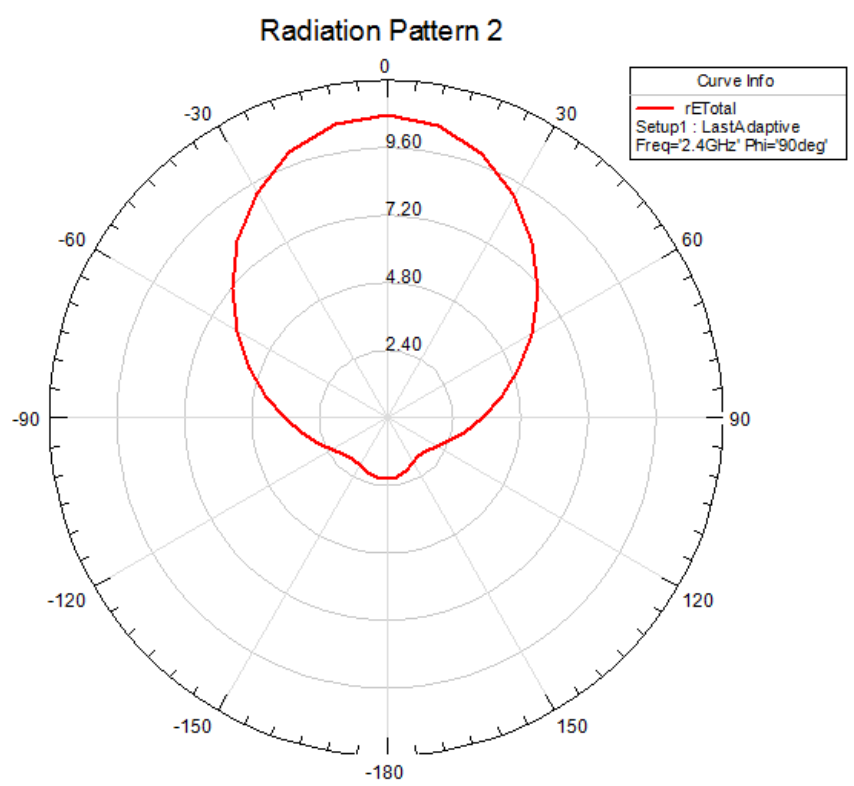

Figure 7: Simulated radiation pattern in the $\mathrm{YZ}$ plane at $1.4 \mathrm{GHz}$

Figure. 8 shows the radiation patterns for proposed fabricated antenna configuration at the resonating frequency of $1.4 \mathrm{GHz}$. 


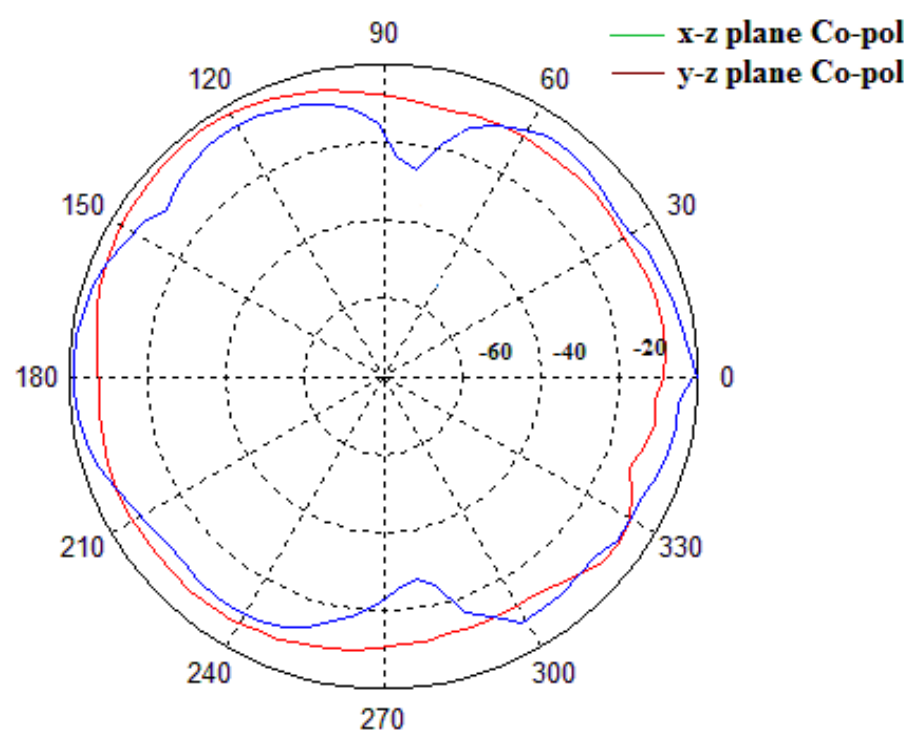

Figure 8: Measured radiation pattern

\subsection{Experimental Setup:}

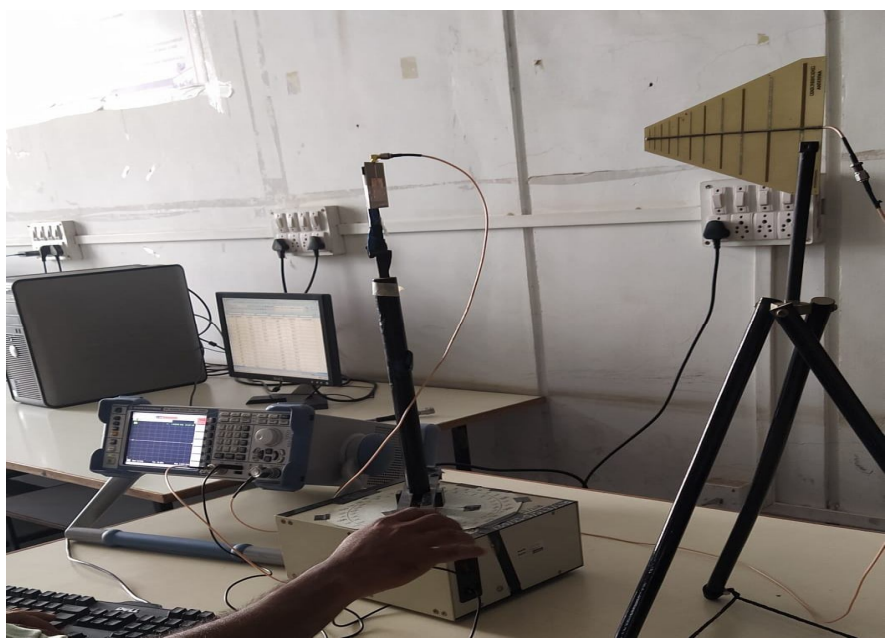

Figure 9. a) : Snapshot of radiation pattern measurement set up

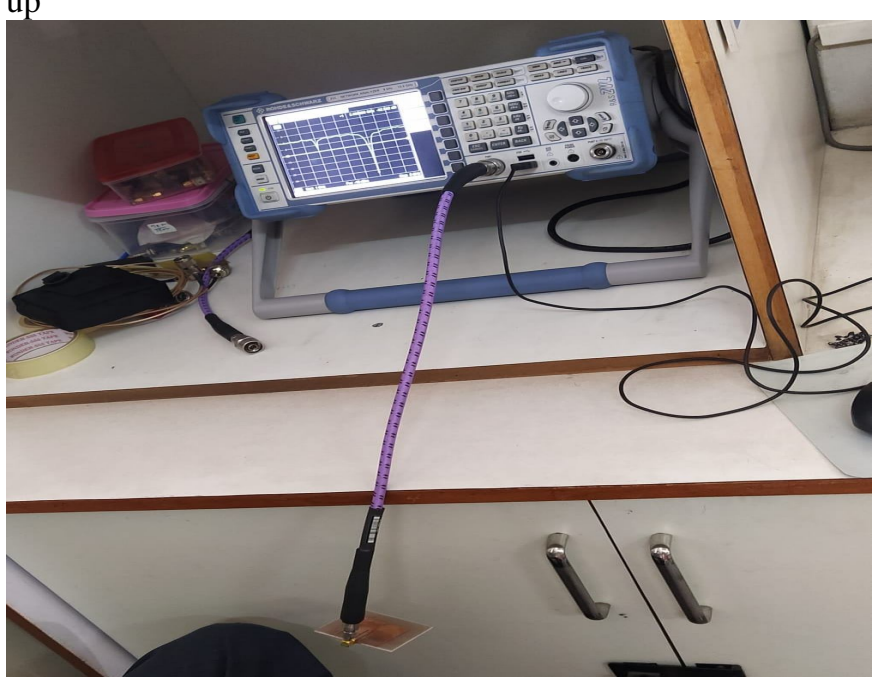

Figure 9. b) : Snapshot of S11 measurement set up by using VNA

\section{CONCLUSION}

In this paper a microstrip patch antenna using metamaterial has been presented. The designed antenna investigated by some parameters like return losses, radiation patterns for wireless applications. The metamaterial substrate provides miniaturization of the antenna. Hence antenna designed for $2.4 \mathrm{GHz}$ but shifts to metamaterial resonance frequency of 1.4GHz. The simulated return loss bandwidth designed FR4 substrate is obtained from 1.4340-1.4580 GHz. Rhode and Schwarz ZVL 135 Microwave Vector Network Analyzer of $13.6 \mathrm{GHz}$ was used to measure the return loss bandwidth. The measured return loss bandwidth of inset fed proposed antenna fabricated on FR4 substrate is obtained from 1.5-1.6 GHz.So such a fabricated antenna can be used for various wireless communication application in the frequency range of 1.5-1.6 $\mathrm{GHz}$.

\section{ACKNOWLEDGEMENT}

Author acknowledges the support provided by Shivaji University, Kolhapur for sponsoring this research work and helping me to find out the required resources in order to complete this project under Research Initiation Scheme.

I also thank institute, KIT's college of Engineering, Kolhapur for the constant support in making this project efficient.

\section{REFERENCES}

1. Aakash Mithari, Uday Patil, Efficiency and Bandwidth Improvement Using Metamaterial of Microstrip Patch Antenna, International Research Journal of Engineering and Technology (IRJET) e-ISSN: 2395 $-0056$

Volume: 03 Issue: 04 | Apr-2016

2. Tamanna Yeasmin Usha, Tarannum Choudhury ,Hanan Ashrafi Anushka, A thesis on Design of Metamaterial Loaded Microstrip Patch Antenna Array, Department of Electrical and Electronic Engineering, BRAC UNIVERSITY

3. Nikhil Kulkarni, G. B. Lohiya, A Compact Multiband Metamaterial based Microstrip Patch Antenna for Wireless communication Applications, Int. Journal of Engineering Research and Application,ISSN : 2248-9622, Vol. 7, Issue 1, ( Part -1) January 2017, pp.01-05.

4. Harender Pal Singh,Ravindra Kumar Yadav, Design and Simulation of Rectangular Microstrip Patch Antenna Loaded with Metamaterial Structure, Electric Electron Tech Open Acc J 1(2): 00012. DOI: 10.15406/eetoaj.2017.01.00012

5. V. Srinivasa Rao, K.V.V.S. Reddy, A.M. Prasad, Bandwidth Enhancement of Metamaterial loaded Microstrip Antenna using Double Layered Substrate, 
Gayatri Vidhate, International Journal of Emerging Trends in Engineering Research, 9(3), March 2021, 193 - 197

Indonesian Journal of Electrical Engineering and Computer Science Vol. 5, No. 3, March 2017, pp. 661 665,DOI: 10.11591/ijeecs.v5.i3.pp661-665

6. Amit K. Singh*, Mahesh P. Abegaonkar, and Shiban K. Koul, Miniaturized Multiband Microstrip Patch Antenna Using Metamaterial Loading for Wireless Application, Progress In Electromagnetics Research C, Vol. 83, 71-82, 2018.

7. Nagarajanv N, Augustine C, Design And Analysis Of Metamaterial Loaded Slotted Rectangular Microstrip Patch Antenna For Quad Band Operation, International Journal of Emerging Technology in Computer Science \& Electronics (IJETCSE) ISSN: 0976-1353 Volume 21 Issue 3 APRIL 2016.

8. Shalina Garg, Ratish Kumar, Multiband Microstrip Patch Antenna for Wireless Applications Using Metamaterial, International Journal of Advanced Research in Electronics and Communication Engineering (IJARECE) Volume 4, Issue 6, June 2015

9. C. A. Balanis, Advanced Engineering Electromagnetics, John Wiley \& Sons, New York, 1989.

10. Website referred: microstrip line Calculator: https://www.emtalk.com/mscalc.php

11. Website referred: www.antenna-theory.com/antennas/patches/pifa.php 